\title{
Pacto entre derrotados ${ }^{1}$
}

\section{Ernesto Sábato}

Hemos fracasado sobre los bancos de arena del racionalismo demos un paso atrás y volvamos a tocar

la roca del misterio

Urs Van Balthasar
Te hablo a vos, y a través de vos a los chicos que me escriben o me paran por la calle, también a los que me miran desde otras mesas en algún café, que intentan acercarse a mí y no se atreven.

No quiero morirme sin decirles estas palabras.

Tengo fe en ustedes. Les he escrito hechos muy duros, durante largo tiempo no sabía si volverles a hablar de lo que está pasando en el mundo. El peligro en que nos encontramos todos los hombres, ricos y pobres.

Esto es lo que ellos no saben, los hombres del poder. No saben que sus hijos también están en esta pobre situación.

No podemos hundirnos en la depresión, porque es de alguna manera un lujo que no pueden darse los padres de los chiquitos que se mueren de hambre. Yno es posible que nos encerremos cada vez con más seguridades en nuestros hogares.

Tenemos que abrirnos al mundo. No considerar que el desastre está afuera, sino que arde como una fogata en el propio comedor de nuestras casas. Es la vida y nuestra tierra las que están en peligro.

Les escribo un verso de Hólderlin:

El fuego mismo de los dioses día y noche nos empuja a salir adelante. iVen! Miremos los espacios abiertos, busquemos lo que nos pertenece, por lejano que esté.

Sí, muchachos, la vida de mundo hay que tomarla como la tarea propia y salir a defenderla. Es nuestra misión.

No cabe pensar que los gobiernos se van a ocupar. Los gobiernos han olvidado, casi podría decirse que en el mundo entero, que su fin es promover el bien común.

La solidaridad adquiere entonces un lugar decisivo en este mundo acéfalo que excluye a los diferentes. Cuando nos hagamos responsables del dolor del otro, nuestro compromiso nos dará un sentido que nos colocará por encima de la fatalidad de la historia.

Pero antes habremos de aceptar que hemos fracasado. De lo contrario volveremos a ser arrastrados por los profetas de la televisión, por los que buscan la salvación en la panacea del hiperdesarrollo. El consumo no es un sustituto del paraíso.

La situación es muy grave y nos afecta a todos. Pero, aún así, hay quienes se esfuerzan por no traicionar los nobles valores. Millones de seres en el mundo sobreviven heroicamente en la miseria. Ellos son los mártires.

Se los ve bajando de los trenes, de los ómnibus, después de inhumanas jornadas de trabajo, o

1 Epílogo del libro Antes del fin. Se cita la edición de bolsillo de Seix Barral, 2004. 
desolados cuando no lo consiguen. Se los ve en las mujeres gastadas a los treinta años por los hijos y la urgencia de salir a trabajar por pagas miserables. Se los ve en los chicos de la calle, en los ancianos que duermen en los subtes. En todos los hombres abandonados en el sufrimiento y en su indigencia.

Una vez le preguntaron a Passolini por qué se interesaba en la vida de los marginados, como el protagonista de Mama Roma, y él respondió que lo hacía porque en ellos la vida se conserva sagrada en su miseria.

En un archivo donde colecciono papeles, recortes que me ayudan a vivir, tengo una fotografía del terremoto que destruyó hace años Concepción de Chile: una pobre india, que ha recompuesto precariamente su ranchito hecho de chapas de zinc y de cartones, está barriendo con una escoba ese pedazo de tierra apisonada delante de su casucha. ¡y uno se hace preguntas teológicas! ¡Cuánto más demostrativa es la imagen de la pobre indiecita que sigue barriendo su casa y cuidando a sus hijos! Esta clase de seres nos revelan el Absoluto que tantas veces ponemos en duda, cumpliéndose en ellos, como dijera Hólderlin, que donde abunda el peligro crece lo que salva.

Cada vez que hemos estado a punto de sucumbir en la historia nos hemos salvado por la parte más desvalida de la humanidad. Tengamos en consideración entonces las palabras de María Zambrano: "No se pasa de lo posible a lo real sino de lo imposible a lo verdadero". Muchas utopías han sido futuras realidades.

Son muchos los motivos, me dirás, podrías decirme, para descreer de todo.

Los jóvenes como vos, herederos de un abismo, deambulan exiliados en una tierra que no les otorga cobijo. En este desguarnecimiento existencial y metafísico, sufren huérfanos de cielo y de techo. Comprendo tu congoja, el desconcierto de pertenecer a un tiempo en que se han derrumbado los muros, pero donde aún no se vislumbran nuevos horizontes. Falsas luminarias pretenden cautivar tu voluntad desde las pantallas. Debés de pensar que no hay un cambio posible cuando el valor de la existencia es menor que el precio de un aviso publicitario. El escepticismo se ha agravado por la creciente resignación con que asumimos la magnitud del desastre. La banalidad con que se degradan los sentimientos más nobles, degenerando al hombre en una patética caricatura, en un ser irreconocible en su humanidad.

Yotambién tengo muchas dudas, y en ocasiones llego a pensar si son válidos los argumentos con que he intentado hallarle sentido a la existencia. Me reconforta saber que Kierkegaard decía que tener fe es el coraje de sostener la duda. Yooscilo entre la desesperación y la esperanza, que es la que siempre prevalece, porque si no la humanidad habría desaparecido, casi desde el comienzo, porque tantos son los motivos para dudar de todo. Pero por la persistencia de ese sentimiento tan profundo como disparatado, ajeno a toda lógica -iqué desdichado el hombre que sólo cuenta con la razón!-, nos salvamos, una y otra vez, sobre todo por las mujeres; porque no sólo dan la vida, sino que también son las que preservan esta enigmática especie. No en vano, en una de las culturas cuyas sabiduría es milenaria, se creía que el alma de una mujer que moría en medio del parto era conducida al mismo cielo que el guerrero vencido en un combate.

Por eso te hablo, con el deseo de generar en vos no sólo la provocación sino también el convencimiento.

Muchos cuestionan mi fe en los jóvenes, porque los consideran destructivos o apáticos. Es natural que en medio de la catástrofe haya quienes intenten evadirse entregándose vertiginosamente al consumo de drogas. Un problema que los imbéciles pretenden que sea una cuestión policial, cuando es el resultado de la profunda crisis espiritual de nuestro tiempo.

Yo reafirmo a diario mi confianza en ustedes. Son muchos los que en medio de la tempestad continúan luchando, ofreciendo su tiempo y hasta su propia vida por el otro. En las calles, en las cárceles, en las villas miseria, en los hospitales. Mostrándonos que, en estos tiempos 
de triunfalismos falsos,la verdadera resistencia es la que combate por valores que se consideran perdidos.

Durante mi viaje a Albania, conocí a un muchacho llamado Walter, que había dejado su casa en la provincia de Tucumán, para ir a cuidar enfermos junto a la congregación de Teresa de Calcuta. Con cuánta emoción lo recuerdo. Siempre que veo las terribles noticias que nos llegan desde aquel entrañable país, me pregunto dónde estará, si acaso leerá estas palabras de reconocimiento a su noble heroísmo.

Son millones los que están resistiendo, vos mismo lo podé s comprobar cuando ves a esos hombres y mujeres que se levantan a altas horas de la madrugada y salen a buscar un empleo, trabajando en lo que pueden para alimentar a sus hijos y mantener honradamente al hogar, por modesto que sea. ¿Te detuviste a pensar cuántos en todo el país comparten esta hambre por la dignidad y la justicia?

Miles de personas, a pesar de las derrotas y los fracasos, continúan manifestándose, llenando las plazas, decididos a liberar a la verdad de su largo confinamiento. En todas partes hay señales de que la gente comienza a gritar: "iBasta!". Lo mismo ocurre con el movimiento zapatista en México, y con todos los movimientos que nos advierten del peligro que corre el futuro del planeta.

Hay que recordar que hubo alguien que derribó al imperio más poderoso del mundo con una cabra y una rueca simbólica. Una salida posible es promover una insurrección a la manera de Ghandi, con muchachos como vos. Una rebelión de brazos caídos que derrumbe este modo de vivir donde los bancos han reemplazado a los templos.

Esta rebelión no justifica de ningún modo que permanezcas en una torre, indiferente a lo que pasa a tu lado. Ghandi advirtió que es una mentira pretender ser no violento y permanecer pasivo ante las injusticias sociales. Por el contrario, creo que es desde una actitud anarcocristiana que habremos de encaminar la vida.
Ya no quedan locos, se murió aquel manchego, aquel estrafalario fantasma en el desierto.

Todo el mundo está cuerdo, terrible, monstruosamente cuerdo.

Esa locura, cuya ausencia León Felipe lamenta, es un acto similar a la del estoico Guevara, cuando abandonó todas las comodidades y partió hacia una lucha insensata en la selva boliviana, enfermo de asma, ya sin remedios para su mal; para terminar asesinado por despiadados y repugnantes bichos. ¿Qué importa si se equivocaba con el materialismo dialéctico? Eso mismo prueba su inocencia, su autenticidad. Luchaba por aquel Hombre Nuevo que hoy nos urge rescatar de los escombros de la historia. En su carta final les dice a los padres: "Queridos viejos, otra vez siento bajo mis talones el costillar de Rocinante, vuelvo a mi camino con mi adarga al brazo"; y entonces sale en busca de 10 que Rilke llamaría su muerte propia. Esa es su grandeza, que algunos considerarán su chiquilinada, su tontería; pero estos gestos de heroísmo demencial son los que nos rescatan de tanta iniquidad, porque no se puede vivir sin héroes, santos ni mártires. Como esos estudiantes que en la plaza de Tian-An-Men, en una horrible masacre, murieron al imponerse ante el implacable acero de los tanques. Son ellos los que nos indican los caminos por los que la vida puede renacer.

Vivimos un tiempo en que el porvenir parece dilapidado. Pero si el peligro se ha vuelto nuestro destino común, debemos responder ante quienes reclaman nuestro cuidado.

Hace poco he visto por televisión a una mujer que sonreía con inmenso y modesto amor. Me conmovió la ternura de esa madre de Corrientes o del Paraguay, que lagrimeaba de felicidad junto a sus trillizos que acababan de nacer en un mísero hospital, sin abatirse al pensar que a éstos, como a sus otros hijos, los esperaba el desamparo de una villa miseria, inundada en ese momento por las aguas del Paraná. ¿No será Dios que se manifiesta en esas madres? ¿Por qué tendría que manifestarse sólo en poetas corno Juan de la Cruz o en las sagradas pinturas de Rouault? 
Si toda la resistencia parece absurda cuando se presiente el fin, épor qué no detenernos a meditar en estos santos? ¿Acaso no son una muestra de que algo existe del otro lado del absurdo?

No sabemos si al final del camino, la vida aguarda como un mendigo que nos extenderá la mano.

Esta fe demencial, o milagrosa, se debe precisamente a que hemos llegado a tocar fondo. Es necesario preservar los lugares que existen hasta en los suburbios de las grandes ciudades, donde aún se conservan los atributos del hombre concreto de carne y hueso.

Cuando el mundo hiperdesarrollado se venga abajo, con todos sus siderántropos y su tecnología, en las tierras del exilio se rescatará al hombre de su unidad perdida. Yquizá, cuando despertemos de esta siniestra pesadilla, cuando un vacío de humanidad nos duela en el pecho, entonces recordaremos que alguna vez fuimos aquello que dijo René Char: "Seres del salto, no del festín, su epílogo".

Me hablás de tu agitación, de una especie de temblor que te sobrecogió y aún perdura, luego de nuestra conversación en aquel café al oírme decir estas palabras.

Debés perdonarme; a pesar de los años, no puedo evitar ser desmesurado en loque considero fundamental.

Por otro lado, ihay temblores que son tan importantes! Porque anteceden a esa clase de decisiones que sacuden los cimientos de nuestra existencia $\mathrm{y}$, aunque generen incomprensión, terminan repercutiendo en el destino de los demás. Los grandes creadores realizan sus obras bajo tensiones similares. Sólo lo que se hace apasionadamente merece nuestro afán, lo demás no vale la pena.

También yo quise huir del mundo. Ustedes me lo impidieron, con sus cartas, con sus palabras por las calles, con su desamparo.

Les propongo entonces, con la gravedad de las palabras finales de la vida, que nos abracemos en un compromiso: salgamos a los espacios abiertos, arriesguémonos por el otro, esperemos, con quien extiende sus brazos, que una nueva ola de la historia nos levante. Quizá ya lo está haciendo, de un modo silencioso y subterráneo, como los brotes que laten bajo las tierras del invierno.

Algo por lo que todavía vale la pena sufrir y morir, una comunión entre hombres, aquel pacto entre derrotados. Una sola torre, sí, pero refulgente e indestructible.

En tiempos oscuros nos ayudan quienes han sabido andar en la noche. Lean las cartas que Miguel Hernández envió desde la cárcel donde finalmente encontró la muerte:

Volveremos a brindar por todo lo que se pierde y se encuentra: la libertad, las cadenas, la alegría y ese cariño oculto que nos arrastra a buscarnos a través de toda la tierra.

Piensen siempre en la nobleza de estos hombres que redimen a la humanidad. A través de su muerte nos entregan el valor supremo de la vida, mostrándonos que el obstáculo no impide la historia, nos recuerdan que el hombre sólo cabe en la utopía.

Sólo quienes sean capaces de encarnar la utopía serán aptos para el combate decisivo, el de recuperar cuanto de humanidad hayamos perdido. 


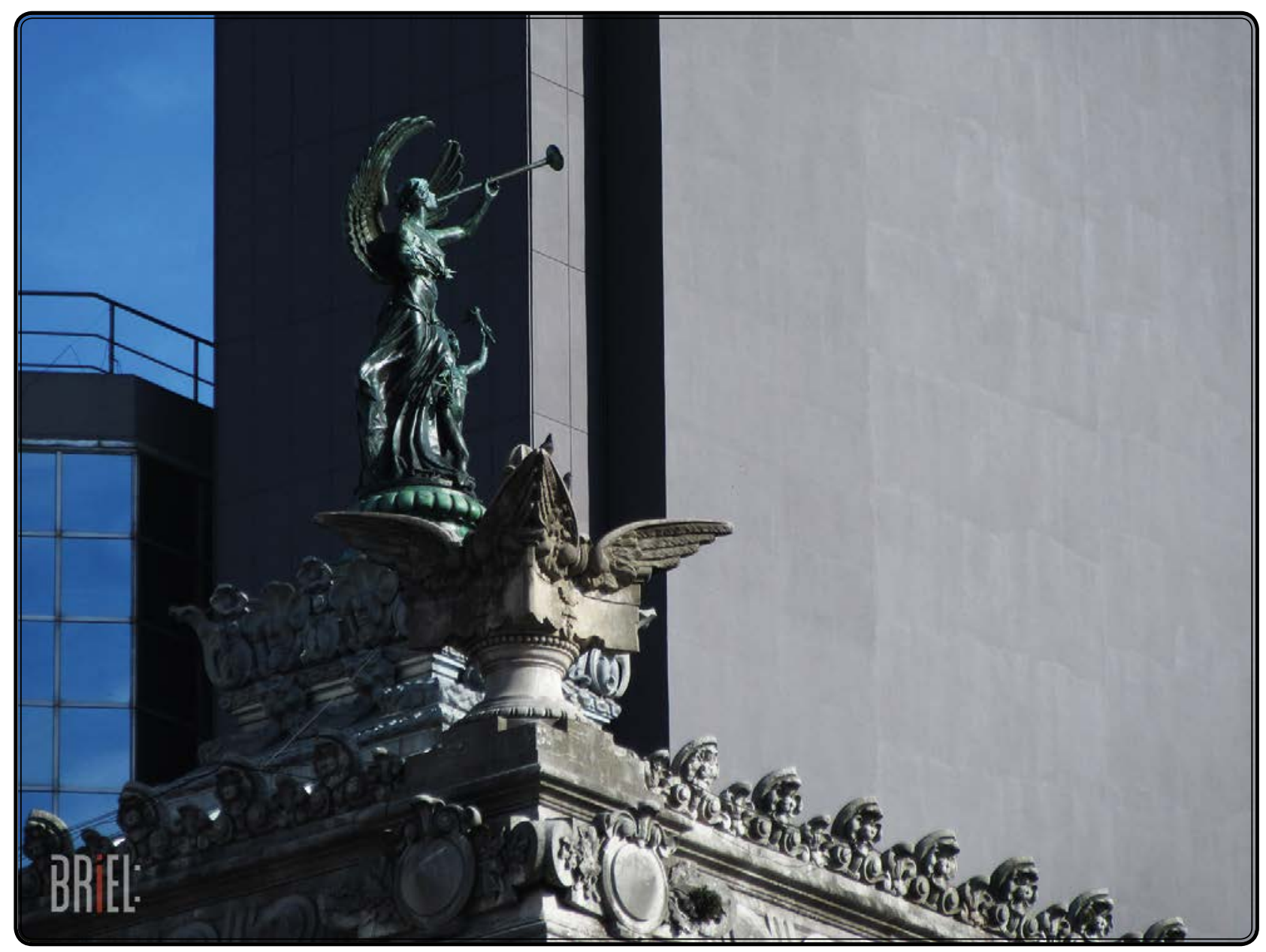

Los edificios que cantan. 